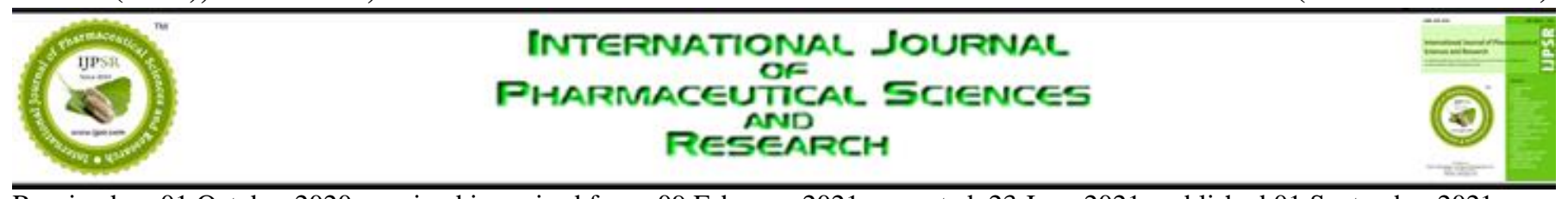

Received on 01 October 2020; received in revised form, 09 February 2021; accepted, 23 June 2021; published 01 September 2021

\title{
STATISTICAL ANALYSIS ON EFFECT OF SITAGLIPTIN AND GLIMEPIRIDE ON PANCREATIC BETA-CELLS DURING THE TREATMENT OF TYPE-2 DIABETIC MELLITUS
}

\author{
Praveen Yadav, Bhaskar Joshi and A. Geetha Bhavani *
}

Department of Chemistry, Noida International University Research Innovation Centre, Noida International University, Gautama Buddha Nagar, Greater Noida - 201308, Uttar Pradesh, India.

Keywords:

Beta-cells, Diabetes mellitus type-2, Glimepiride, Sitagliptin

Correspondence to Author:

Neeraj

Department of Chemistry,

Noida International University

Research Innovation Centre, Noida

International University, Gautama

Buddha Nagar, Greater Noida -

201308, Uttar Pradesh, India.

E-mail: ageethabhavani@gmail.com
ABSTRACT: The study aimed to analyze the treatment of Sitagliptin with Glimepiride to improve pancreatic beta-cells in T2DM patients. Beta cells are a type of cell found in the pancreatic islet and also synthesize, secrete insulin and amylin. Sitagliptin is found to be maintaining the betacells function and glycemic control in T2DM patients. Randomly diabetes mellitus type-2 (T2DM) patients' data is collected (110 patients) for statistical analysis. For this study, T2DM patients enrolled with the age of 30-60 years, treated with Sitagliptin and Glimepiride once a day. The baseline of $\mathrm{HbA} 1 \mathrm{c}>7.0 \%$ to $<10.5 \%$; thus, the performed student t-test is to find out the significant role. The 110 patients are distributed into two groups: one Sitagliptin user group $(n=62)$ and the second Glimepiride user group $(n=43)$. The sitagliptin treatments may also protect also beta cells as the pancreas may not able to regenerate beta-cell.
INTRODUCTION: Diabetes mellitus type-2 (DMT2) is a metabolic disorder to hyperglycemia and dysfunction of the pancreas and insulin resistance or deficiency of insulin. DMT2 is a serious public health disease and globally increases in number by year over year. Metformin is a firstline of treatment for diabetes patients; on the other hand, single anti-hyperglycemic agents are unsuccessful at achieving the target results in patients, so clinicians preferred combination therapies1 for effective DMT2 treatment. Insulin resistance is a cause of hyperglycemic so monotherapy with metformin is the most commonly used oral hypoglycemic agent regimen to treat patient with diabetes mellitus type-2.

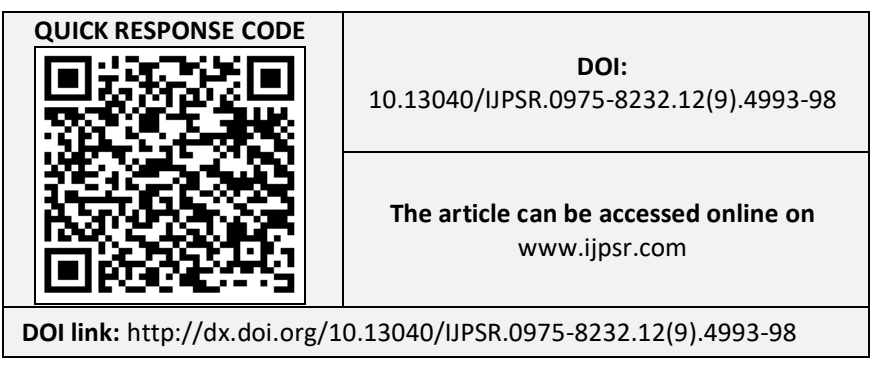

The usage of sitagliptin is in regular practice to improve blood glucose level by stimulating insulin secretion from pancreatic beta-cells in a nonglucose dependents manner ${ }^{2}$. Sitagliptin is practiced as a single dosage medicine daily and highly selective to dipeptidyl peptidase-4 (DPP-4) in many countries for diabetes mellitus patients treatment ${ }^{3}$.

According to the report of UKPDS $16^{4}$ the type- 2 diabetes mellitus patients are treated with a combination or add-on drug to gradually improve insulin pancreatic beta-cell function. Sitagliptin treatment promising effect of reducing antiinflammatory effect due to multiple actions and effecting the T-Lymphocyte and monocyte clinical usefulness of the add-on therapy with Sitagliptin for DMT2 would decrease glycaemic ${ }^{5}$. In addition, DDP-4 inhibitor effect of a pancreatic beta-cell has been demonstrated in animal models ${ }^{6}$ to show the effect and indicators of beta-cell function. A high $\mathrm{P} / \mathrm{I}$ ratio suggests a high proportion of proinsulin (pre-stage peptide of insulin) among the secreted 
insulin, which may indicate beta-cell dysfunction. Recently, Terauchi et. al., ${ }^{7}$ reported that sitagliptin exhibited a lowering effect in $\mathrm{P} / \mathrm{I}$ whereas Glimepiride had no such effect in Japanese elderly type- 2 diabetes patients. The present study aims to analyze DMT2 patients treated with sitagliptin with Glimepiride to improve pancreatic beta cells in type- 2 diabetic patients and compared the study to examine glucose levels irrespective of age groups.

Methodology: The patient's data having the diabetic history for last 2 years to 8 months with the age group between $<30$ years to $<60$ years data is collected for analysis. All patients are under treatment with combination oral agents or without insulin therapy. This study's open-label randomized T2DM patients study was conducted at the Felix multi-specialty hospital, Noida U.P with enrolled patients from $1^{\text {st }}$ Oct, 2017 to 30st Sept, 2019. The study requirement, the study protocol was conducted with the approval of the ethic committee of the Noida International University, U.P (NERB/SOS/CHEM/18/106) as per requirements of on need. This patient's blood glucose level is noted at the starting time of study and found to be from $<125 \mathrm{mg} / \mathrm{dl}$ to $400 \mathrm{mg} / \mathrm{dl}$. The complete methodology of patient selection is shown in Fig. 1.

The inclusion criteria parameters are (i) all patients diagnosed diabetic history (ii) age between 30 years to 60 years (iii) $\mathrm{HbA} 1 \mathrm{c}>6.9 \%$ to $<10.5 \%$. The exclusion criteria parameter is (i) patients were already diagnosed with retinopathy, neuropathy, malignancy (ii) upper age $>70$ years excluded in the inclusion criteria, (iii) if patients history of ketosis, (iv) surgical treatment for severe infection, (v) symptoms of renal disease (serum creatinine level $>1.6 \mathrm{mg} / \mathrm{dl}$ ), (vi) history of Hepatic and malignancy and (vii) pregnancy, history of allergy. Only these are patients enrolled in the study when they full file the inclusion criteria.

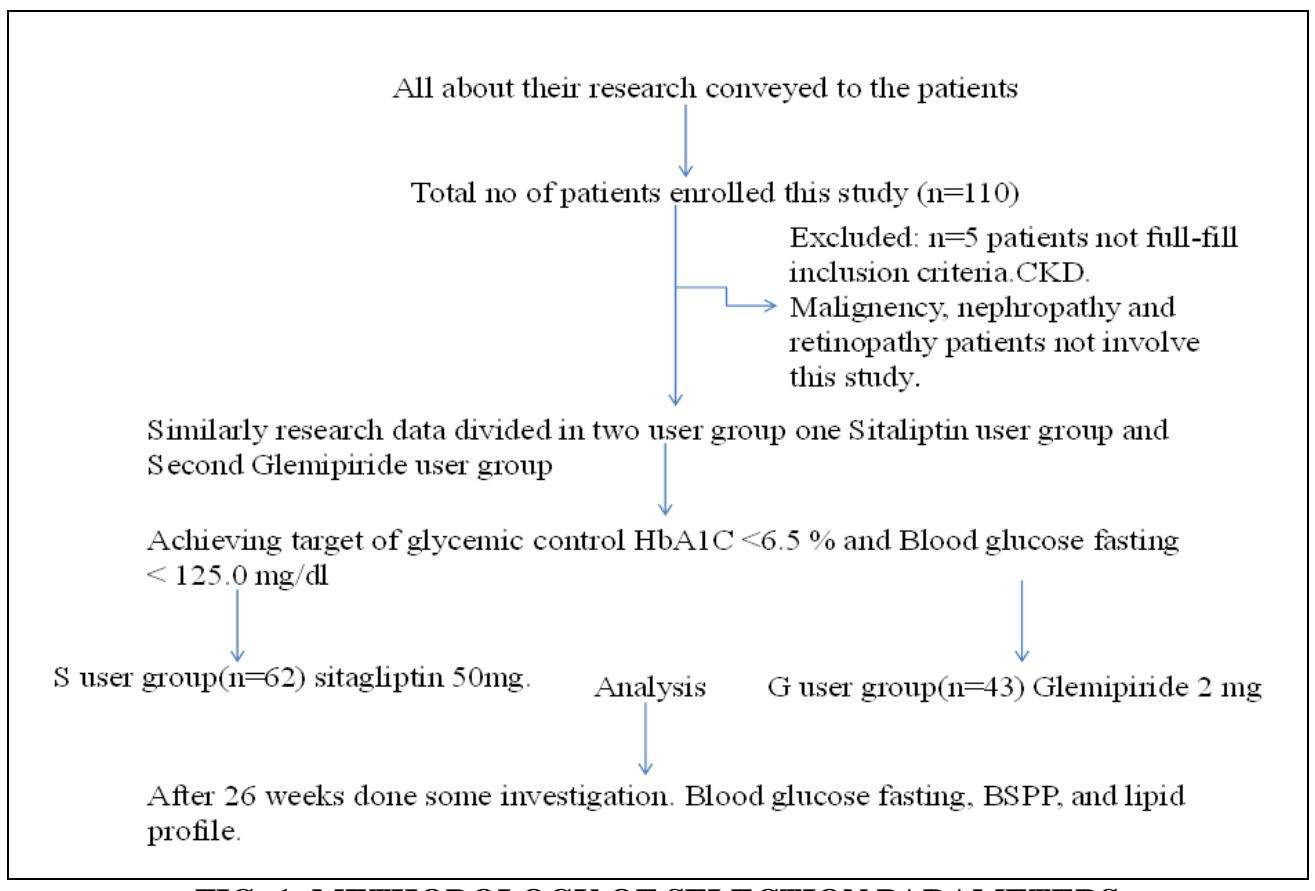

FIG. 1: METHODOLOGY OF SELECTION PARAMETERS

The patients are randomly divided into two user groups: sitagliptin user group. Patients use sitagliptin $50 \mathrm{mg}$ once a daily and the second glimepiride user group which patients use Glimepiride $2 \mathrm{mg}$ once a daily. The target glycemic control was set HbA1c $<6.5 \%$ and fasting glucose $<125 \mathrm{mg} / \mathrm{dl}$. After 26 weeks of treatment, we are done fasting glucose, $2 \mathrm{~h}$ post-meal, HbA1c, lipid profile data shown in Table 3.
The primary hypothesis for the study was that sitagliptin $(50 \mathrm{mg})$ is non-inferior to Glimepiride and improvement of pancreatic beta-cell and glycemic control in 26 weeks of combination therapy. The chi-square test was used to analyze the patient's data and perform the 'p' test. SD Mean calculated by mathematical formulas and level of significance analyzed by the null hypothesis. 
TABLE 2: CLINICAL CHARACTERISTICS AND DEMOGRAPHICAL DATA OF PATIENTS

\begin{tabular}{|c|c|c|c|}
\hline \multirow[t]{2}{*}{ Tests } & ${ }^{a} \mathrm{~S}$ user group $\mathrm{n}=62$ & ${ }^{b}$ G user group $n=43$ & 'p' value \\
\hline & Mean \pm SD & Mean \pm SD & \\
\hline Age (years) & $55.61 \pm 5.17$ & $54.88 \pm 5.67$ & 1 \\
\hline Blood glucose fasting $(\mathrm{mg} / \mathrm{dl})$ & $183.25 \pm 56.44$ & $167.46 \pm 30.12$ & 0 \\
\hline Blood glucose pp (mg/dl) & $218.98 \pm 65.32$ & $205.19 \pm 41.66$ & 0 \\
\hline $\mathrm{HbA} 1 \mathrm{c} \%$ & $8.16 \pm 0.86$ & $7.92 \pm 0.84$ & 0.63 \\
\hline SGOT(Aspartate- aminotransferase) & $32.47 \pm 21.27$ & $39.53 \pm 26.46$ & 0 \\
\hline SGPT(Alanine aminotransferase) & $32.81 \pm 14.21$ & $43.44 \pm 22.24$ & 0 \\
\hline Total cholesterol $(\mathrm{mg} / \mathrm{dl})$ & $173.0 \pm 35.85$ & $185.12 \pm 32.12$ & 0 \\
\hline Triglyceride (mg/dl) & $154.2 \pm 48.62$ & $199.30 \pm 50.01$ & 0 \\
\hline HDL-cholesterol (mg/dl) & $43.76 \pm 7.33$ & $42.88 \pm 5.88$ & 0.2 \\
\hline
\end{tabular}

${ }^{\mathrm{a}} \mathrm{S}$ user group: Sitagliptin; ${ }^{\mathrm{b}} \mathrm{G}$ user group: Glimepiride; $\mathrm{n}$ : number of patients

Result of the Statistical Analyses: The primary characteristics of the patients are shown in Table 2. The total number of patients $\mathrm{n}=105$ and sitagliptin user group $n=62$ and Glimepiride user group $n=43$ and done to calculate mean \& standard deviation (SD) and p-value, after diagnosis of diabetes mellitus by HbA1C respectively, Mean age (54.88 \pm 5.67 years in sitagliptin and $55.61 \pm 5.17$ years in Glimepiride, respectively and p-value is 1.0 ), blood glucose fasting-BGF $(187.39 \pm 65.94 \mathrm{mg} / \mathrm{dl}$ in sitagliptin and $155.50 \pm 48.79 \mathrm{mg} / \mathrm{dl}$ in Glimepiride, respectively), blood glucose postprandial-BGPP $(218.32 \pm 78.0 \mathrm{mg} / \mathrm{dl}$ in sitagliptin and $166.0 \pm 48.08 \mathrm{mg} / \mathrm{dl}$ in Glimepiride, respectively), $\mathrm{HbA1c} \%(8.25 \pm 1.48 \%$ in sitagliptin and $8.65 \pm 1.91 \%$ in Glimepiride and the p-value is (0.63), respectively. After 26 weeks, the treatment percentage of $\mathrm{HbA1c}$, blood glucose fasting and lipid profile level is found to decrease significantly as shown in Table 3, respectively. Data indicates the DPP-4 inhibitors present in sitagliptin influence insulin secretion by enhancing the glycogen like peptide-1 (GLP-1). The DPP-4 enzyme activity is inhibited by GLP-1 incretin function continue for insulin production.

Insulin level increases in blood glucose level will become down significantly. The treatment with sitagliptin glycosylated hemoglobin level in body maintained. DPP-4 inhibitor does not increase body weight, sitagliptin also decreases the postprandial level and triglyceride level.

\begin{tabular}{|c|c|c|c|}
\hline \multirow[t]{2}{*}{ Test } & ${ }^{a} \mathrm{~S}$ user group $\mathrm{n}=62$ & ${ }^{b} G$ user group $n=43$ & 'p' value \\
\hline & Mean \pm SD & Mean \pm SD & \\
\hline Blood glucose fasting $(\mathrm{mg} / \mathrm{dl})$ & $123.39 \pm 21.88$ & $134.49 \pm 17.44$ & 0 \\
\hline Blood glucose $\mathrm{pp}(\mathrm{mg} / \mathrm{dl})$ & $157.60 \pm 25.99$ & $168.02 \pm 22.57$ & 0 \\
\hline $\mathrm{HbA} 1 \mathrm{C} \%$ & $6.29 \pm 0.30$ & $6.54 \pm 0.27$ & 1 \\
\hline Total cholesterol(mg/dl) & $162.50 \pm 26.11$ & $172.09 \pm 26.20$ & 0 \\
\hline Triglyceride(mg/dl) & $150.06 \pm 38.32$ & $182.74 \pm 35.12$ & 0 \\
\hline HDL-cholesterol(mg/dl) & $44.47 \pm 4.06$ & $43.19 \pm 3.62$ & 1 \\
\hline
\end{tabular}

${ }^{a} \mathrm{~S}$ user group: sitagliptin; ${ }^{\mathrm{b}} \mathrm{G}$ user group: Glimepiride; n: number of patients. All values for HbA1c expressed as \%

Data were compared between the two groups using unpaired ' $t$ ' test for measurement data the ' $p$ ' value and mean, standard deviation calculate after 26 weeks treatment with sitagliptin and glimepiride anti-hyperglycemic oral agents. The results of after 26 weeks data were found to be mean is 123.39 , and SD-21.88 value of blood glucose fasting treated by sitagliptin and mean-134.49 and SD17.44 is Glimepiride, respectively. The value of HbA1c for same patients has to drop down from baseline in comparison of starting values. After 26 weeks the HbAlc $(6.29 \pm 0.30 \%$ in sitagliptin and
$6.54 \pm 0.27 \%$ in glimepiride and p-value is 1.0 ), respectively. At 26 weeks, the patients achieving target $\mathrm{HbA} 1 \mathrm{c}$ of $<6.5 \%$ with sitagliptin $(50 \mathrm{mg})$ were significantly higher compared to Glimepiride (2mg) therapy. However, there was a significant effect on the change in $\mathrm{HbA} 1 \mathrm{c}$ percentage at 26 weeks is due to DPP-4 inhibitor activity of DPP-4 enzyme blockage, and GLP-1 incretin is actively help in the production of insulin and glucagon.

DISCUSSION: Parameters of patient selection criteria is made on the basis of HbAlc because 
blood sugar levels of most people are used to fluctuate depending on individual physical conditions like stress level and intake meal composition. The best parameter of HbA1c is from $>6.9 \%-<10.5 \%$ to selected among the data of diabetic patients. Fig. 2 reflects the blood glucose fasting graph of the effect of the drug on clinical data after 26 weeks of sitagliptin $(50 \mathrm{mg})$ treatments. This graph is also clearly showing the considerable effect on glycaemic control level. Diabetes is a progressive disease; glycemic control is directly associated with the onset and progression of retinopathy and nephropathy. The oral antidiabetic drugs and DDP-4 inhibitors influence endogenous incretin function and control with the help of glucose homoeostasis without increasing the risk of unexpected weight gain and hypoglycaemia ${ }^{8,9}$.

Sitagliptin, such as anti-inflammatory, effect on monocytes and T-lymphocytes, the clinical usefulness of the addition of sitagliptin in T2DM could beyond glycemic reduction, secondary effects like prevention of weight gain, may be expected from the addition of sitagliptin to diabetes treatment ${ }^{10,11}$. The Fig. 2 blood glucose level after $2 \mathrm{~h}$ duration of post-meal significant the effect on glycaemic control by treatment of 26 weeks with sitagliptin (50mg). Diabetes awareness programs help the patients to reduced fear a discourage option, which provide the potential for poorly glycemic control. Diabetes treatment with insulin is at risk of developing hypoglycemic.

The treatment with sitagliptin DPP-4 inhibitor inhibited plasma DPP-4 activity, inhibition of plasma DPP-4 activity sitagliptin increases in active GLP-1 and gastric inhibitory polypeptide levels influence to increase the insulin and $\mathrm{C}$ peptide index level also reduced the blood glucagon level and reduced glycemic excursion ${ }^{12}$ was found in an animal experiment with the treatment of sitagliptin. This experiment also observed the pancreatic beta cells protecting, and the growth-promoting effect shows ${ }^{13}$. HbA1c mean standard more reduced in case of sitagliptin with similar metformin study conducted by Sato et al. ${ }^{14}$. In type-2 diabetes mellitus patient's sitagliptin with metformin significantly good control of blood plasma glucose ${ }^{15}$ and also no risk of hypoglycemia. A significant difference in data was found from the test values of the treatment beginning and after treatment of sitagliptin $(50 \mathrm{mg})$ regimen. In type- 2 diabetes mellitus patients, betacell not secrete proper insulin, so plasma glucose level increased. Sitagliptin protects Beta-cell by growth-promoting effect ${ }^{16}$. With the help of data analysis sitagliptin with metformin was more effective than compare to Glimepiride.

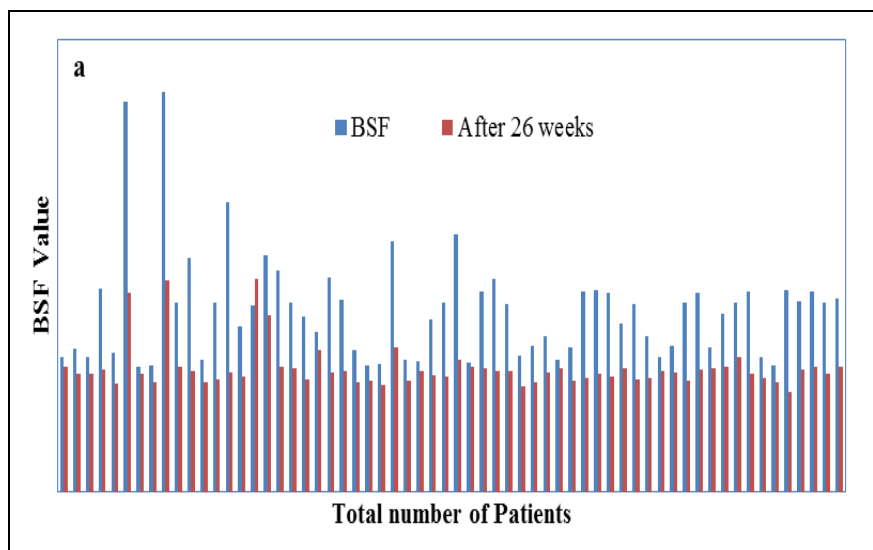

FIG. 2: GRAPHICAL PRESENTATION OF BLOOD GLUCOSE FASTING RESULTS BEFORE AND AFTER TREATMENT OF SITAGLIPTIN (50 MG)

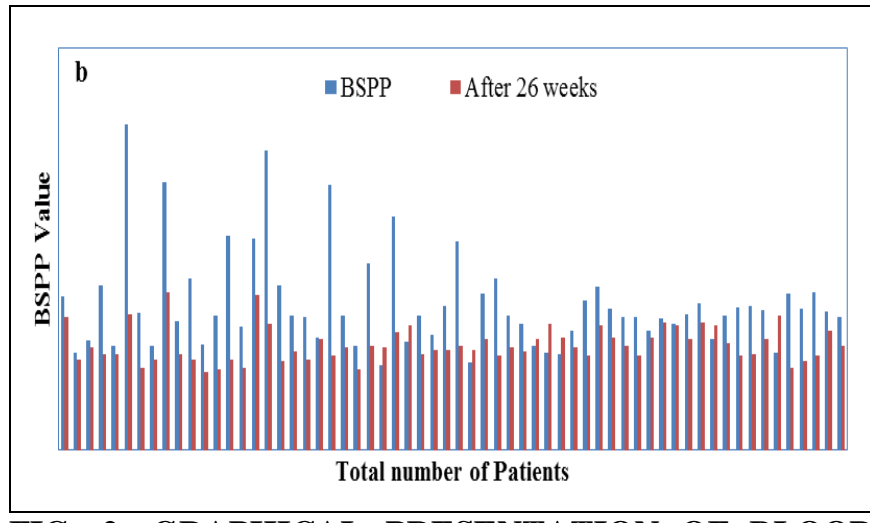

FIG. 2: GRAPHICAL PRESENTATION OF BLOOD GLUCOSE PP (2H POST MEAL) RESULTS BEFORE AND AFTER TREATMENT OF SITAGLIPTIN (50MG)

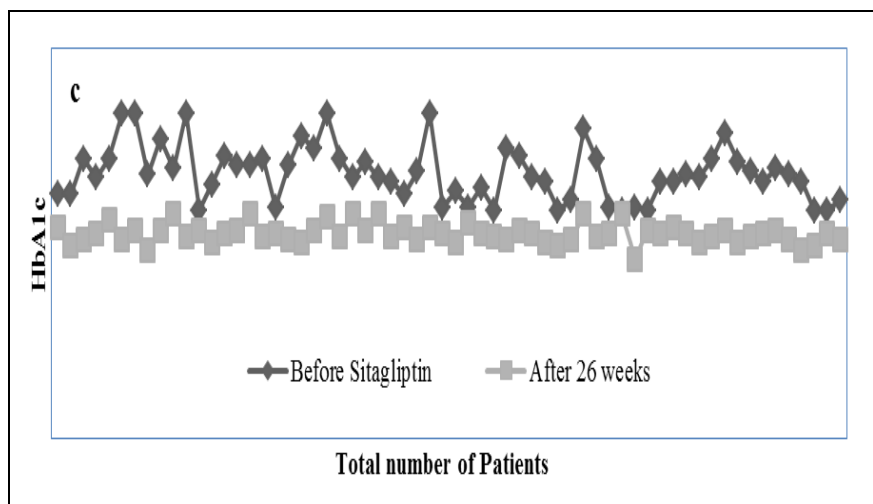

FIG. 2: GRAPHICAL PRESENTATION GLYCOSYLATED HAEMOGLOBIN (HBA1C) RESULTS OF BEFORE AND AFTER TREATMENT OF SITAGLIPTIN (50MG) 
Fig. 2 confirms the HbA1c \% value after 26 weeks of treatments of sitagliptin $(50 \mathrm{mg})$ shows a significant effect on glycemic control. This is maybe due to DPP-4 in inhibited the DPP-4 enzyme activity; therefore insulin production increase inside the body and reduce the glucose level. Fig. 3 shows the variation in blood glucose fasting level over the 26 weeks of treatments of glimepiride regimen. The glimepiride directly out on ATP-dependent $\mathrm{K}^{+}$channel of pancreatic betacells. This cause a positive ion increase inside Beta cells and the action potential, active potential enhance the $\mathrm{Ca}^{++}$channel of beta-cells for the moment of $\mathrm{Ca}^{++}$ion inside from the outside. These $\mathrm{Ca}^{++}$ions bind with stored insulin and reduce it from beta cells released insulin reduced continues of glycosylated hemoglobin and blood glucose level. As shown in Fig. 3, the change in HbAlc \% level over the 26 weeks treatment period of Glimepiride. Glimepiride inhibited the ATPdependent $\mathrm{K}^{+}$channel of bets cells to generated positive action potential to activate $\mathrm{Ca}^{++}$channel by which outside $\mathrm{Ca}^{++}$moves inside beta cells. These $\mathrm{Ca}^{++}$release stored insulin from beta cells. At 26 weeks, the primary goal of treatment is to target glycemic control by maintaining the HbAlc level near $6 \%$ to $6.5 \%$ shown in Table 3. The study expected and found that without any sort of side effect to control the blood sugar level by using combination therapy. Gastrointestinal side effects such as nausea, vomiting, or diarrhea were observed ${ }^{17}$. In this study, the dosage was regulated according to the protocol, so it helps fore minimizing gastrointestinal adverse effects ${ }^{18}$.

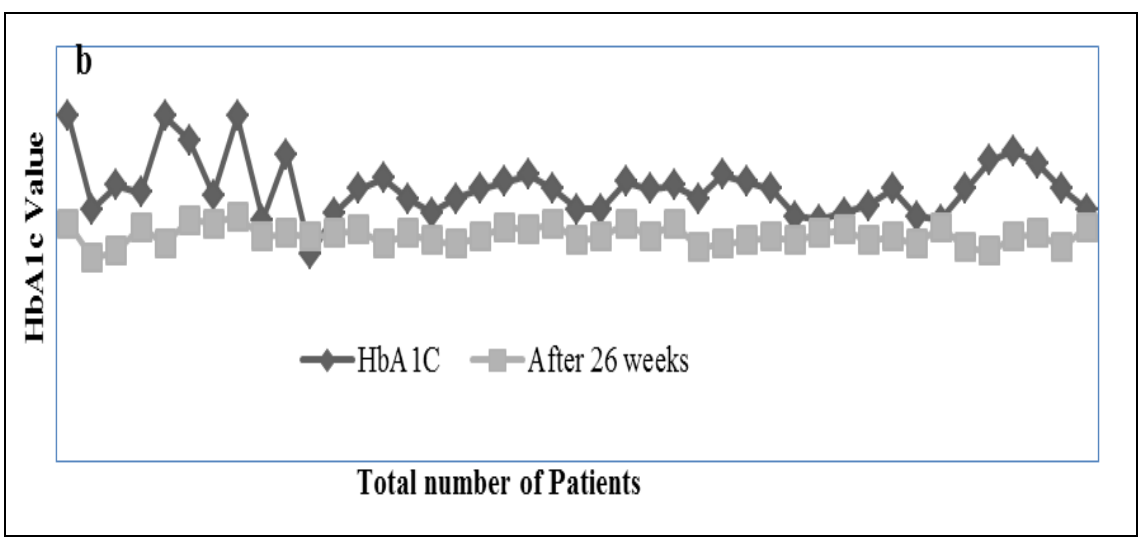

FIG. 3: GRAPHICAL PRESENTATION OF HBA1C RESULTS OF BEFORE AND AFTER TREATMENT WITH GLIMEPIRIDE (2MG)

CONCLUSION: The present studies intended on analyze the collected data of sitagliptin $(50 \mathrm{mg})$ with metformin treatment over type-2 diabetics. The inadequate increase efficiency with better tolerance is seen in type- 2 patients; the result shows control glucose level.

The comparison to Glimepiride with sitagliptin (50mg) found more effective to T2DM patients in treatments of achieving greater glycosylated hemoglobin. In nutshells, the present study concludes the for better beta-cell function of protectiveness, DDP-4 inhibitor protective effect has satisfaction outcome.

ACKNOWLEDGEMENT: I would like to express my deep gratitude to Prof. (Dr.) Jayanand and Dr.Varun Kumar Sharma from Noida International University Research and Innovations Centre for approving the present study.
I also express my most profound sense of gratitude to Dr. D.K. Gupta, Chairman of Felix hospital Noida, U.P, Dr. Shilpi Gupta Department of Microbiology, School of Science, Amity University, U.P., Mr. Raviprakash Maurya, Department of Pathology, Felix hospital Noida and Ms. Sweeti Kushwaha, Department of Pathology, Sharda university \& Hospital, Greater Noida, U.P. for their valuable guidance, assistance and time to time inspiration throughout my research.

\section{CONFLICTS OF INTEREST: Nil}

\section{REFERENCES:}

1. Tumer RC, Cull CA, Frighi V and Holman RR: Glycaemic control with diet, sulfonylurea, metformin, or insulin in patients with type-2 diabetes mellitus: progressive requirement for multiple therapies (UKPDS 49). UK prospective diabetes study Group (UKPDG) 2005-2012; 281(21). 
2. Dore JW, Thompson ME, Wilde CE and Sewell PF: Diet and oral anti-diabetic drugs and plasma sugar and insulin level in patient with maturity-onset diabetes mellitus. $\mathrm{Br}$ Med J 1976; 1: 498-500.

3. Harman GA, Bergman A and Stevens C: Effect of single oral dose of sitagliptin, a dipeptidyl peptidase-4 (DDP-4) inhibitor, on incretin and plasma glucose levels after an oral glucose tolerance test in patients with type- 2 diabetes. J Clin Endo Crinol Metab 2006; 91: 4612-19.

4. U.K prospective diabetes study 16 . Overview of 6 years therapy of type-2 diabetes: a progressive disease Prospective Diabetes Study Group. Diabetes 1995; 44(11): 1249-58.

5. Scheen AJ: Cardiovascular effects of gliptins. Nature Reviews Cardiology 2013; 10:73-84.

6. Seck T, Nauck M, Sheng D, Sunga S, Davies MJ, Stein PP and Kaufman KD: safety and efficacy of treatments with sitagliptin od glipizide in patients with type-2 diabetes inadequately controlled on metformin: a 2-years study. Int J Clin Pract 2010; 64(5): 562-76.

7. Terauchi Y, Yamada Y, Ishida H, Ohsugi M, Kitoaka M, Satoh J and Yeba D: Efficacy and safety of sitagliptina compared with Glimepiride in Japanese patients with type 2 diabetes mellitus aged $\geq 60$ years. Diabetes Obes Metab 2017; 19(8):1188-92.

8. Bae EJ: Dipeptidyl peptidase-IV inhibitors in diabetes complication: role of DDP-4 beyond glucose control. Arch Pharm. 2016; 39(8): 1114-28.

9. Lindenmeyer A: Interventions to improve adherence to medication in people with type 2 diabetes mellitus: a review of the literature on the role of pharmacists. Journal of Clin Pharmacy and Therapeutics. 2006; 31(5): 409-19.

10. Scheen AJ: Cardiovascular effect of Sitagliptin. Nature Reviews Cardiology. 2013; 10: 73-84.

11. Kerr D and Phillip M: Improved glycaemic control in poorly controlled patients with type 1 diabetes using real- time continuous glucose monitoring. Diabetes Care 2006; 29: 2730-32.

12. Herman GA, Bergman A, Stevens C and Kotey P: Effect of single oral doses of sitagliptin, a dipeptidyl peptidase-iv inhibitor, on incretin and plasma glucose levels with type2 diabetes. J Clin Endocrinol Metab dio 2006; 10: 121009.

13. Mu J, Woods J and Zhou YP: Chronic inhibition of DPP-4 with sitagliptin analog preserves pancreatic beta-cell mass and function in a rodent model of type 2 diabetes. Diabetes 2006; 55: 1696-04.

14. Sato S, Saisho Y, Kou K, Meguro S, Tanaka M and Irie J: Efficacy and safety of sitagliptin added to insulin in Janpanes patients with type-2 diabetes. PloS one. 2015; 10(3): e0121988.

15. Pasquel PJ, Gianchandani R and Rubin DJ: Efficacy of Sitagliptin for the hospital management of general medicine and surgery patients with type- 2 diabetes. Lancet Diabetes Endocrinol 2017; 5(2): 125-3.

16. Shi C, Zhang R, Bai R, Liu D, Wang Y and Zhang X: Efficacy and safety of sitagliptin added to metformin and insulin compared with voglibose in patients with newly diagnosed type-2 diabetes. Clinics 2019; 74: e736.

17. Htike ZZ, Zaccardi F, Papamargaritis D, Webb DR, Khunti K and Davies MJ: Efficacy and safety of glucagonlike peptide-1 receptor agonists in type 2 diabetes: a systematic review and mixed-treatment comparison analysis. Diabetes, Obesity and Metabolism 2017; 19 (4): 524-36.

18. Davies M, Pieber TR, Hartoft-Nielsen ML, Hansen OKH, Jabbour S and Rosenstock J: Effect of oral semaglutide compared with placebo and subcutaneous semaglutide on glycemic control in patients with type 2 diabetes: a randomized clinical trial. JAMA 2017; 318(15): 1460-70

\section{How to cite this article:}

Yadav P, Joshi B and Bhavani AG: Statistical analysis on effect of sitagliptin and glimepiride on pancreatic beta-cells during the treatment of type-2 diabetic mellitus. Int J Pharm Sci \& Res 2021; 12(9): 4993-98. doi: 10.13040/IJPSR.0975-8232.12(9).4993-98.

All @ 2021 are reserved by International Journal of Pharmaceutical Sciences and Research. This Journal licensed under a Creative Commons Attribution-NonCommercial-ShareAlike 3.0 Unported License.

This article can be downloaded to Android OS based mobile. Scan QR Code using Code/Bar Scanner from your mobile. (Scanners are available on Google Playstore) 